\title{
Prescribing trends in patients of the pain-clinic in a tertiary care teaching hospital, Hapur, Uttar Pradesh
}

\author{
Saborni Dey ${ }^{1}$, Vivek Sinha ${ }^{2}$, Poonam Kachhawa ${ }^{3}$ \\ ${ }^{1}$ Assistant Professor, Department of Pharmacology, Saraswathi Institute of Medical Sciences, Hapur, UP, India, \\ ${ }^{2,3}$ Associate Professor, Department of Biochemistry, Saraswathi Institute of Medical Sciences, Hapur, UP, India
}

Background: The drug utilization research is a significant constituent of medical audit which helps in monitoring, evaluating and building required modifications in the prescribing practices to secure a rational and cost effective medical care. The study of prescribing patterns also important for the marketing, distribution, prescription and use of drugs in society, with special emphasis on the resulting medical, social and economic consequences. Aims and Objective: Drug prescribing studies aim to provide feedback to the prescriber and to create awareness among them about rational use of medicines. The current study aims to evaluate standard drug utilization pattern of analgesics like Nonsteroidal anti-inflammatory drugs (NSAIDs) in a Medical College \& hospital, SIMS, Hapur. Material and Methods: This prospective, observational study was conducted in the out-patient department of the Pain Clinic during six months period to evaluate the prescribing pattern of analgesics along with monitoring of WHO prescribing indicators in a tertiary care teaching hospital. After getting approval by Institutional Ethical committee, random prescriptions were collected from the OPD and scanned for the record purpose. The demographic data and the prescription was taken from 340 prescriptions. Data was evaluated as per WHO prescribing indicator guidelines along with definitive statistical analysis of data done. Results: A total 340 prescriptions were investigated. The result revealed that NSAIDs as Diclofenac $(75.21 \%)$ and Paracetamol $(14.88 \%)$ were the most commonly prescribed analgesics. Average number of drugs in the present study was found to be 2.29. Percentage of drugs prescribed generic name was $(21.02 \%)$. Percentage of encounters with an antibiotic was $(12.95 \%)$. The use of injectable preparation was around (7.20\%). Out of all the medicines, $(85.90 \%)$ were found written from Essential Drug List. Conclusion: The prescribing trend of NSAIDs indicate some deviation from the WHO recommendations. This touchstone data will be useful to plan more targeted research and to improve prescribing practices. These types of studies help to design policy for rational use of drugs and periodic training programs of physicians, establishing drug and therapeutic committee, drug information centres and regular educational interventions that can be beneficial for improving prescribing practice with rational drug usage.

Key words: Prescribing trend; Analgesics; Pain; Observational study
Access this article online

Website:

http://nepjol.info/index.php/AJMS

DOI: 10.3126/ajms.v10i4.24214

E-ISSN: 2091-0576

P-ISSN: 2467-9100

\section{INTRODUCTION}

Pain is an unpleasant sensory and emotional experience associated with actual and potential tissue damage or described in terms of such damage. ${ }^{1,2}$ Nonsteroidal antiinflammatory drugs (NSAIDs) are universally used to treat inflammatory, painful conditions by inhibiting Cyclooxygenase (COX-1 or non-selective or COX-2 selective) enzyme. NSAIDs are well accepted over-the-counter drugs used for acute, chronic non traumatic musculoskeletal conditions such as arthritis, backache, myalgia as well as in traumatic injury, fracture, wound, post operative pain 
etc. ${ }^{3}$ Periodic evaluation of drug utilization template is advantageous to validate more suitable modifications in the prescription of drugs to increase the therapeutic benefit and decrease the adverse effects. Prescription pattern of NSAID has transformed in quick succession over a period of time as these are the most widely prescribed class of medications worldwide. ${ }^{3}$

Drug utilization study define the intensity and characterization of recent drug usage trends, optimal quality of drugs and compliance with regional or national guidelines like generic drugs, essential drug formulations.It was observed in the majority of such studies that physicians do not adhere to theguidelines made by regulatory agencies; leading to irrational use of medicines, treatment failure, drug resistance, adverse effects and economic burden with poor patient compliance.Prescription monitoring studies ensure a bridge between rational drug usage, evidence based medicine, pharmaco-economics, pharmacovigilance, pharmacogenetics and eco-pharmacovigilance.

The optimum purpose of drug utilization studies are useful to assign the appropriate quality of drug therapy by identifying, documenting and analyzing problems in drug usage and monitoring the consequences of interventions. Prescriptions are a good source of information for determining some of the indicators of drug use recommended by WHO including the:

- Average number of drugs per prescription;

- Percentage of drugs prescribed by generic name;

- Percentage of encounters resulting in prescription of an antibiotic;

- Percentage of encounters resulting in prescription of an injection;

- Percentage of drugs prescribed from essential drugs list or formulary, and

- Average drug cost per encounter. ${ }^{4}$

There were limited data on drug utilization practices in patients attending Pain Clinic. These knowledge's are useful to evaluate the present state and future trends of drug usage, to estimate crudely disease prevalence, drug expenditures, appropriateness of prescriptions and adherence to evidence-based recommendations.

\section{AIMS AND OBJECTIVE}

The present study was undertaken to scrutinize the drug utilization pattern mainly to analgesics like Nonsteroidal anti-inflammatory drugs (NSAIDs) in urban and rural populations of Hapur. The study also inspected whether the physicians were abiding by standard WHO prescription indicators during prescribing drugs.

\section{MATERIAL AND METHODS}

\section{Study design}

A prospective, observational study design was undertaken in the patients attending the Pain Clinic Out-patient Department in association with Pharmacology Department of a tertiary care teaching hospital, SIMS, Hapur, Uttar Pradesh.

\section{Study area}

The study was conducted in District Hapur (UP), India.

\section{Study period}

The duration of the study was of six months from September 2017 to February 2018.

\section{Study setting}

The study was initiated by the patients being referred to the Department of Pain Clinic, Saraswati Institute of Medical Sciences and Hospital, Hapur (Uttar Pradesh).

\section{Study population}

The present study included 340 cases attending outpatient of Pain Clinic. Before participation, the purpose of the study was explained to all the patients and their written informed consent was taken. In the clinic during consultation information obtained regarding demographic characteristics of the patient and detailed history of the disease were taken. Each prescription contained diagnosis of disease, drug name, dose, dosage form, strength, frequency of drug administration, drug route, duration of treatment, drug dispense quantity and patient drug knowledge.

In this study, random prescriptions were collected from the OPD and scanned for the record purpose. The data were archival in nature and scrutinized thoroughly as per WHO prescribing indicators that include accurate prescribing pattern, patient care and facility specific indicators by using defined methodology of WHO. ${ }^{5}$

The prescription of the patients treated with analgesics as NSAIDs with some co-prescribed drugs were assembled for the study. In addition, all types of fixed drug combinations were excluded.Core drug prescribing indicators include, average number of drugs per prescription, percentage of total generic drugs prescribed, percentage encounter who received at least one antibiotics, percentage encounter who received at least one injection and percentage of drug recommended from Essential Drug List (EDL).

In Core health facility or Complementary indicators, availability of key drugs, availability of copy of National 
Essential drug list, average consultation \& dispensing time, percentage of drugs adequately dispensed \& labeled at the pharmacy, patient's knowledge of correct dosage could not be evaluated \& determined accurately.

\section{Statistically analysis}

At the end of data collection, all data were tabulated in summary sheets and were analyzed by using computer software SPSS version 21. Descriptive statistics were used to describe data. No follow up of prescriptions done. P-value less than 0.05 was considered significant.

\section{Ethical approval}

Ethical Approval was taken from the Institutional Ethical Committee after explaining the aim and objectives of the Study.

\section{Detailed procedure}

All patients underwent a detailed clinical and laboratory evaluation during the study.

\section{RESULTS}

Total number of drugs prescribed in prescriptionsof the total 340 patients was 780 . Prescriptions of all 340 patients were analyzed, of whom $212(62.35 \%)$ were males while $128(37.65 \%)$ were females. Average number of drugs per prescription was $2.29 \&$ had shown the preference towards poly-pharmacy.

Figure 1 showing three types of formulations that were prescribed to the patients - oral, parenteral, topical. The number of oral, parenteral and topical prescriptions in the study population was 714 (91.53\%), $56(07.20 \%)$, and $10(1.30 \%)$ respectively.

Table 1 showing the types of medicines prescribed included nonsteroidal anti-inflamatory drugs (NSAIDs) $242(31.03 \%)$, antacid or anti-ulcerants 195 (25\%), antimicrobial agents 101 (12.95\%), calcium and vitamin
D tablets 117 (15\%), corticosteroids 31 (3.97\%) and other drugs $94(12.05 \%)$. Among the other drugs polyvitamins, multimineral, ferrous sulfate, folic acidwere advised.

Table 2 shows the percentage of encounters with an injection prescribed was $56(7.20 \%)$ that is lesser than WHO ideal 10\% injectable usage. So, it indicates rational use of injections but still should be needed proper guidance to minimize parenteral formulations. Dose frequency and duration of treatment was mentioned in $100 \%$ prescriptions. No diagnosis or provisional diagnosis was made in 18 prescriptions and investigations

\begin{tabular}{|c|c|}
\hline Types of Medicines & Number of Drugs Prescribed \\
\hline NSAIDs & $31.03 \%$ \\
\hline Antacid/Anti-Ulcerant & $25 \%$ \\
\hline Anti-Microbial agents & $12.95 \%$ \\
\hline Calcium and Vit-D tablets & $15 \%$ \\
\hline Corticosteroids & $3.97 \%$ \\
\hline Others & $12.05 \%$ \\
\hline
\end{tabular}

\section{Table 2: Standard prescibing trends followed in} SIMS

\begin{tabular}{|l|c|}
\hline PRESCRIBING INDICATORS & RESULT \\
\hline Average number of drugs per prescription & 2.29 \\
\hline $\begin{array}{l}\text { Percentage of drugs prescribed from Essential drug } \\
\text { list }\end{array}$ & $85.90 \%$ \\
\hline Percentage of drugs prescribed by Generic name & $21.02 \%$ \\
\hline Pereentage of drugs prescribed as NSAIDs & $31.03 \%$ \\
\hline Pereentage of encounter with an Injection prescribed & $7.20 \%$ \\
\hline Pereentage of Anti-Uleerant drugs prescribed & $25 \%$ \\
\hline Percentage of most frequently prescribed NSAID & $75.21 \%$ (Diclofenac Sodium) \\
\hline $\begin{array}{l}\text { Perentage of encounter with an Antibiotic } \\
\text { prescribed }\end{array}$ & $12.95 \%$ \\
\hline
\end{tabular}

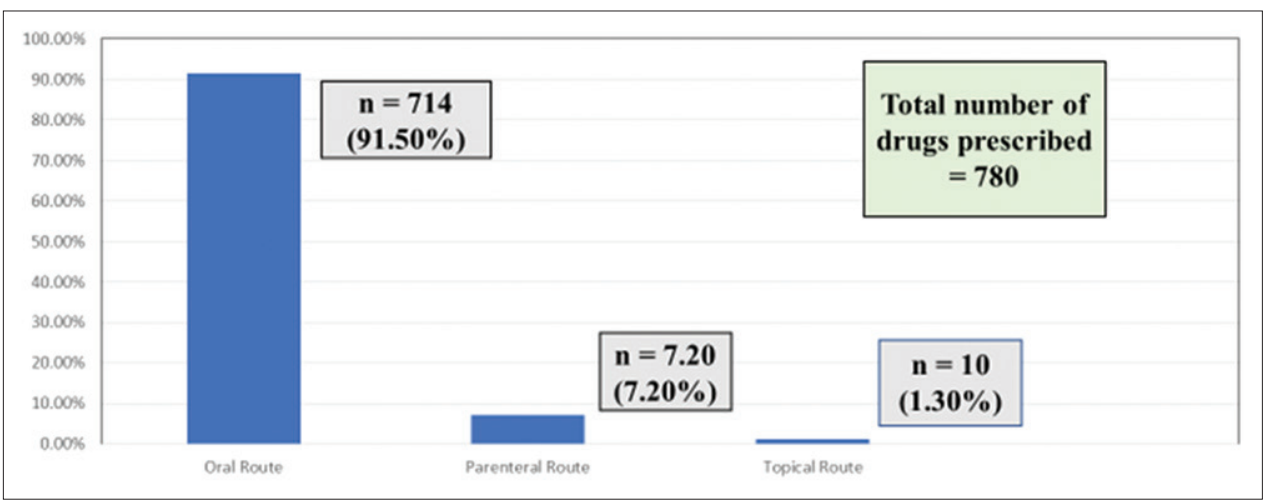

Figure 1: Different types of formulations prescibed in pain clininc out-patient department 
were advised for accurate detection of disease. Out of all the medicines, $670(85.90 \%)$ were found written from Essential Drug List; that help to monitor whether National drug policy is being used or not according to National Essential Drug List. In the prescribing indicators the percentage of drugs prescribed by generic name was $164(21.02 \%)$.

Figure 2 shows the most frequently prescribed NSAIDs were Diclofenac sodium $182(75.21 \%)$, Paracetamol $36(14.88 \%)$, Aceclofenac 8 (3.31\%), Ibuprofen 6 (2.48\%), Piroxicam 5 (2.06\%), Rofecoxib 5 (2.06\%).

\section{DISCUSSION}

A prescription based analysis is regarded as one of the most effective methods to assess and evaluate the prescribing attitude of the physicians. In this study, the average number of drugs per prescription was found to be 2.29 , which is slightly more than the WHO recommendations. It has been endorsed that the limit of number of drugs written per prescription should be two as poly-pharmacy increase cost of medicines, drugdrug interactions, adverse drug reactions \& poor patient compliance. A hospital based study in Bangladesh had reported a mean of two. ${ }^{6}$ The mean number of drugs was more than two in some other studies. ${ }^{7-9}$ Where the number was lesser than two in another study. ${ }^{10,11}$ The most common clinical indications for using NSAIDs were various joint pains, musculoskeletal pain, backache, arthritis, traumatic injury \& infective conditions etc. In this study, NSAIDs were the most frequently prescribed medicine $(31.03 \%)$. A study in a teaching hospital in Western Nepal was comparable with our recent data. ${ }^{11}$ Mostly the drugs were administered in the tablet or capsule form $(91.53 \%)$ followed by injectables $(7.20 \%)$ and with least use of gel/creams/ointments $(1.30 \%)$. The use of injectable preparation was more $(7.20 \%)$ as compared to a study from New Delhi (4.4\%). ${ }^{12}$

During the study, the percentage of drugs prescribed from Essential Drug List were (85.90\%) and it was not identical with the WHO Standard (100\%) which serve as an ideal. In some other studies performed by B.K. Mohanty et al (57.70\%) and NY Mirza et al $(77.61 \%)$ the results were lower than our outcomes. ${ }^{13,14}$ The Percentage of drugs prescribed from Essential Drug List (85.90\%), almost matches the mean from 8 different Studies of $(71.70 \%) .{ }^{15}$ Drugs prescribed by Generic name was $(21.02 \%)$ that is not identical with WHO Standard of $(100 \%) .{ }^{16}$ The results of several other studies were $(30.70 \%)$ more than our studies while some shows less use of Generic drugs (5.41\%) \& $(5.75 \%)$ respectively. ${ }^{13,17,18}$ This study Spotlight the repeated use of NSAIDs (31.03\%) in Pain clinic out patients as pain is a common symptoms over there. The most commonly encountered NSAID was Diclofenac Sodium (75.21\%) followed by Paracetamol (14.88\%), while other NSAIDs as Aceclofenac (03.31\%), Ibuprofen (02.48\%), Piroxicam $(02.06 \%)$ \&Rofecoxib $(02.06 \%)$ were least prescribed drugs. This prescription pattern was much similiar with some other studies. ${ }^{7,11,19}$

Most of the conditions in patients are degenerative in nature and also having a disease progressive course. So,

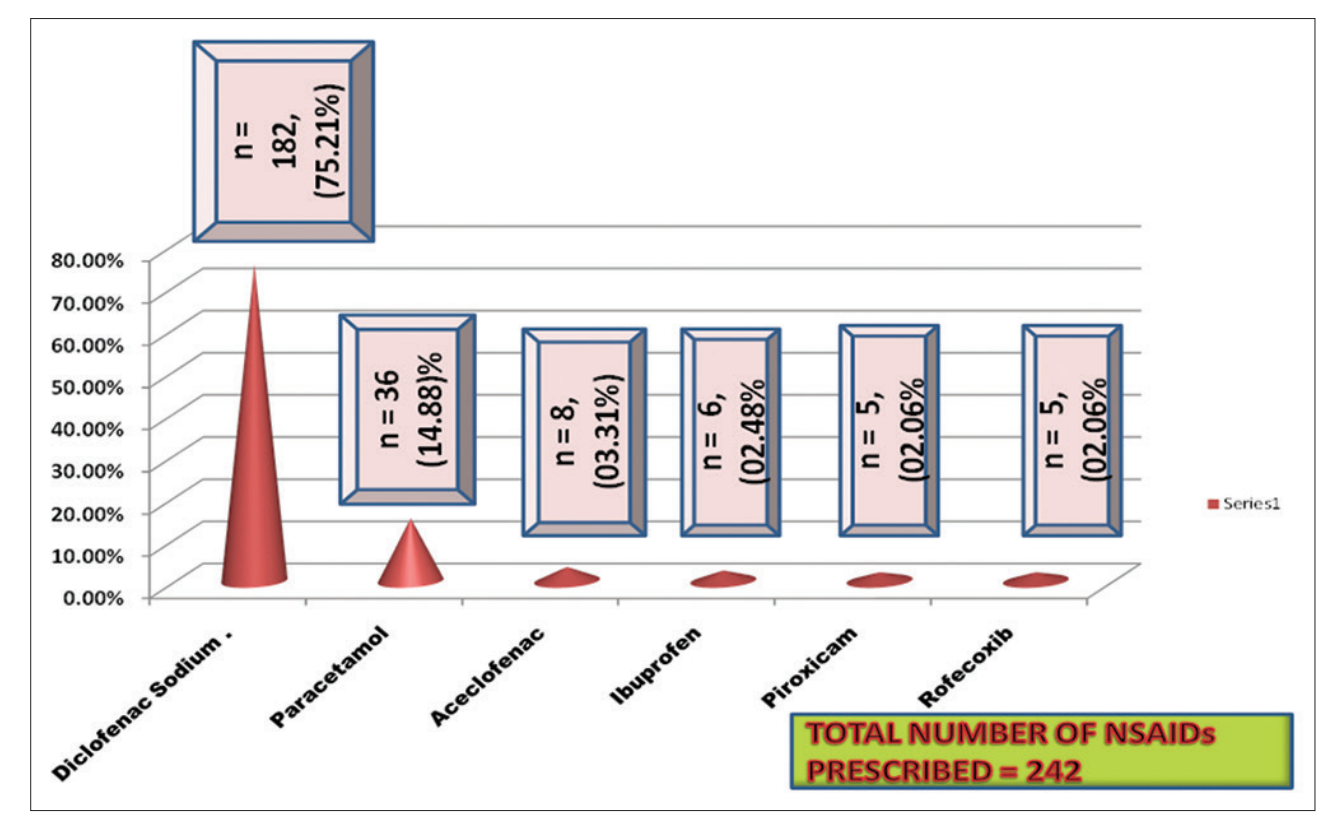

Figure 2: Various types of analgesics or NSAIDS prescribed in pain clinic out-patient department, SIMS 
patients have to prescribe synergistic adjuvant drugs such as calcium \&Vit-D tablets (15\%), anti-ulcerants $(25 \%)$, corticosteroids (3.97\%) and other medications as folic acid, ferrous sulphate, multivitamins and minerals, rubefacients $(12.05 \%)$ to refine overall health benefits. Even though GI toxicity is major limitation of traditional NSAIDs, there were no significant toxicity occurred during the study. Diclofenac, Paracetamol are relatively safe in short term use ( $<10$ days) and we have also avoided prolonged usage of these drugs to decrease peptic ulcer. So, anti-ulcerant was prescribed only with $(25 \%)$ patients. Another study from tertiary care hospital in Maharashtra by Madhuri Kulkarni showed resemble with our data $(23.8 \%)$. This indicates that anti-ulcer drugs should be used in selective patients with NSAIDs and with other associated risk factors. $^{20}$

Along with NSAIDS different other classes of drugs were also prescribed like antimicrobial agents $(12.95 \%)$. In several other studies it was seen that percentage of encounters with antibiotic was $78.15 \%{ }^{17}$ and $60 \%{ }^{21}$ respectively. This study reveals that we are using antimicrobials with precaution to prevent antibiotic resistance. WHO also has been trying to control the emergence of resistance to antibiotics and also spread the message for rational use of antibiotics.

\section{CONCLUSION}

The prescribing course of NSAIDs point out some divergence from the WHO standard. The study showed some irrational practice mainly with non-generic drug usage and more inclination towards injectables but the percentage of analgesics prescribed from essential medicine list, use of less antimicrobial agents, antiulcerants and other drugs were found to be satisfactory. The average number of drugs per prescription was slightly more. So, the study highlights the need to minimize the average number of drugs per encounter and also to select cost effective drugs judiciously. Thus, we conclude revision of clinical policy is essential with better interventions to improve drug use and quality control at all possible levels for long term and better clinical outcome in the medical practice.

\section{REFERENCES}

1. Kumar HK and Elavarasi P. Definition of pain and classification of pain disorders. J. Advanced Clin \& Research Insights 2016; 3:87-90.

2. Tabish A, Jha RK, Rathod AM, Rathod RM and Gupta KK. Prescribing trends of analgesics in a tertiary health care setup of rural Vidarbha. Res J Pharm Biol Chem Sci 2012;3:566-571.

3. Kumar A, Dalai CK, Ghosh AK and Ray M. Drug utilization study of co-administration of nonsteroidal anti-inflammatory drugs and gastro-protective agents in an orthopedic outpatient department of a tertiary care hospital in West Bengal. Int J Basic Clin Pharmacol 2013; 2:199-202.

4. WHO: World Health Organization. Rational use of Medicines. Available from http://www.who.int/medicines/areas/rational_use/ en/index.html.

5. Geneva: World Health Organization/DAP/93. WHO;1993. How to investigate drug use in health facilities. Selected drug use indicators, 1993.

6. Afsan M, Alam MM, Noor $\mathrm{N}$ and Ahmed HHA. Prescribing practices in the out-patient department in a tertiary care teaching hospital in Bangladesh. Updat Dent Coll J 2012; 2(2):13-17.

7. Mohammed AA, Waf FB, Sultan AO, Mahmoud MA. Prescribing patterns of nonsteroidal anti-inflammatory drugs (NSAIDs) at out-patient departments of four hospitals. Biomedical Research 2018;29(19):3643-3647.

8. Ubedulla S, Sekhar NC, Jayasree T, Shankar J and Rohit K. Journal of Chemical and Pharmaceutical Research 2013; 5(11):512-517.

9. Rishi RK, Sangeeta S, Surendra K and Tailang M. Prescription audit: experience in Garhwal (Uttaranchal), India. Trop Doct 2003; 33:76-79.

10. Choudary KD and Bezbaruah KB. Prescribing patterns of analgesics in orthopaedic in-patient department at tertiary care hospital in Guwahati, Assam, Northeast India. Indian J Pharmacol 2016;48(4):377-381.

11. Shankar PR, Pai R, Dubey AK and Upadhyay DK. Prescribing patterns in the orthopaedics out patient department in a teaching hospital in Pokhara, Western Nepal. Kathmandu University Medical Journal 2007;5(17):16-21.

12. Biswas NR, Biswas RS, Pal PS, Jain Sk, Malhotra SP, Gupta A, et al. Patterns of prescriptions and drug use in two tertiary hospital in Delhi. Indian J Physiology Pharmacology 2000; 44:109-112.

13. Mohanty BK, Ashwini M, Hasamni's AA, Patil SS, Murti KSN, et al. Prescription pattern of the department of a tertiary care hospital in Rajamundry, India. J of Clin and Diag Research 2010; 4:2047-2051.

14. Mirza NY, Desai $S$ and Ganguly B. Prescribing pattern in a pediatric out-patient department in Gujarat. Bangladesh J Phar2009; 4:39-42.

15. WHO medicines situation. Apps. Who. int/medicinedocs/pdf/ s6160e/s6160e.pdf.

16. Isah AO, Ross-Degnan D, Quick J, Laing R and Mabadeje AF. The development of standard values for the WHO Drug use Prescribing Indicators. ICUM/EDM/WHO.

17. Ajapuje P, Dhengre P, Giri VC and Khakse GM. Drug prescription practices among pediatric patients in Yavatmal, Central India. Int Jof Recent Trends in Sci and Tech 2012; 5(2):104-106.

18. Simpson GB and Choudary GN. Comparative analysis of prescription writing by teaching and non-teaching clinicians in and around Guntur. International Journal of Recent Trends in Sciences and Technology 2012;5(2):100-103.

19. Sharif SI, Al- Shaqra M, Hajjan H, Shamout A and Wess L. Pattern of drug prescribing in a hospital in Dubai, United Arab Emirates. Lybian J Med 2005; 070928:10-12.

20. Madhuri K and Patil A. Drug utilization study in the orthopedics outpatient department of a tertiary care hospital in Maharashtra. Asian J of Pharmaceutical \& Clin Research 2018; 11(9):224-226.

21. Chandra S, Khan IN, Mateenudin M, Chandrakapure A, Maaz S, et al. Drug utilization study of a tertiary care hospital in a rural area of Jalna, Maharashtra, India by using WHO prescribing indicators. Int J of Clin \& Basic Pharmacol 2018;7(1):55-58. 
Authors Contribution:

SD- Concept and design of study, manuscript preparation, data collection, statistically analyzed and interpreted, critical revision of the manuscript; VS-Reviewed the literature, helped in preparing of the first draft of manuscript, critical revision of the manuscript; PK- Collected data, statistically analyzed and interpreted, review of the manuscript.

\section{Work attributed to:}

Department of Pharmacology and Pain clinic, Saraswathi Institute of Medical Sciences, Hapur, Uttar Pradesh, India.

Orcid ID:

Dr.Saborni Dey - (10 https://orcid .org/0000-0002-3433-1612

Dr. Vivek Sinha - (1) https://orcid.org/0000-0002-9073-0917

Dr. Poonam Kachhawa - (1) https://orcid.org/0000-0002-5982-240X

Source of Support: Self funding, Conflict of Interest: None declared. 